\title{
Epidemiology/Population
}

\section{Abortion in the Republic of Sakha (Yakutia): Incidence and Trends}

\author{
Natalia I. Douglas, $\mathrm{PhD}, \mathrm{ScD}^{1}$; Yana G. Rad', $\mathrm{PhD}^{1}$; Vyacheslav G. Chasnyk, $\mathrm{PhD}, \mathrm{ScD}^{2}$; \\ Tatiana E. Burtseva, PhD, ScD ${ }^{3}$; E.A. Borisova ${ }^{4,1}$; L.A. Shek ${ }^{5}$; Tatiana Y. Pavlova, $\mathrm{PhD}^{5}$ \\ ${ }^{1}$ North-Eastern Federal University, the Russian Federation \\ ${ }^{2}$ Saint-Petersburg State Pediatric Medical University, the Russian Federation \\ ${ }^{3}$ Yakut Research Centre for Complex Medical Problems, the Russian Federation \\ ${ }^{4}$ Medical Center of Yakutsk, the Russian Federation \\ ${ }^{5}$ The Ministry of Health of the Republic of Sakha (Yakutia), the Russian Federation
}

\begin{abstract}
Background: The abortion incidence is influenced by many medical and socioeconomic factors. In some way, it indicates the wellbeing of the population, and the abortion statistics can show the ways to improve medical services and to raise the living standards of people. The objective of the study was to estimate the abortion incidence and to describe its current trends in the Republic of Sakha (Yakutia) (the RS(Y)).

Materials and Methods: The study was designed as a population-based descriptive study, based on the results of a longitudinal analysis of national and regional reports of the Yakut healthcare services and an analysis of medical records describing 34,220 abortions among women living in all regions of Yakutia, which occurred between 2010 and 2014 and in the first 9 months of 2015.

Results: The absolute number of abortions performed each year, the rate of abortions per 1,000 women of fertile age, and the rate of abortions per 100 deliveries declined $(P<0.01)$ by about $37 \%, 32 \%$ and $37 \%$, respectively, between 2006 and 2014 . The rate of abortions per 1000 women of fertile age in the first 9 months of 2015 decreased by $1.3 \%$, compared to the same period of $2014(P=0.05)$. Though the number of abortions in primigravida women decreases every year, the percentage of them is still rather high, especially at the age of 20 to 24 and 15 to 19 , accounting for approximately $2.4 \%$ of all abortions. The relative number of miscarriages before 12 weeks of pregnancy increased. Changes in the relative number of abortions performed between 12 to 21 weeks of pregnancy characterized by a decrease in the percentage of miscarriages from 2012 to 2015 and a dramatic increase in the percentage of therapeutic abortions.

Conclusion: The revealed trends of the absolute number of abortions and the rates of occurrence in the RS(Y) can be considered in total as favorable, but compared to the data obtained in Russia in total, the dynamics of these trends cannot be regarded as satisfactory. Simplicity of medication abortions can lead to an increase in the absolute number of abortions, especially in adolescents and young women. Analysis of spatial and temporal distribution of the incidence of abortions did not reveal any association with the ethnicity of women.(Int J Biomed. 2016;6(3):218-221.).
\end{abstract}

Key Words: abortion incidence • adolescents • primigravida women • reproductive health care.

\section{Introduction}

Abortion care is known to be a critical component of comprehensive reproductive health care. According to WHO, in 2008, an estimated 43.8 million induced abortions were performed throughout almost all major regions of the

*Corresponding author: Tatiana E. Burtseva, PhD, ScD. Yakut Research Centre for Complex Medical Problems, the Russian Federation.E-mail: bourtsevat@yandex.ru world, a slight decline from 45.6 million in 1995. Developing countries accounted for $86 \%$ of all induced abortions..$^{[1,2]}$ The United Nations defines the policy on fertility level in Russia in total, and particularly in Yakutia, as "no intervention" and qualifies the grounds on which abortion is permitted as "least restrictive" (to save a woman's life, in case of rape or incest, and because of fetal impairment). ${ }^{[3]}$

In the Republic of Sakha (Yakutia) (the RS(Y)), women have the fundamental right to abortion as determined by the law. The decision to continue or terminate a pregnancy 
belongs to the pregnant woman, and the decision makers are not restricted by regulations that limit or delay access to care. The Ministry of Health Care of the RS(Y) tracks yearly the news on demography indices and abortion in order to perform management duties and to implement the federal policies, procedures and regulations in a timely manner.

According to the World Factbook, in 2015 Russia ranked 179th among 224 countries in the latest global survey with its 1.61 estimated total fertility rate. ${ }^{[4,]}$ Though the trends of demographic indices in the RS(Y) are rather favorable (Fig.1), fertility can still be increased.

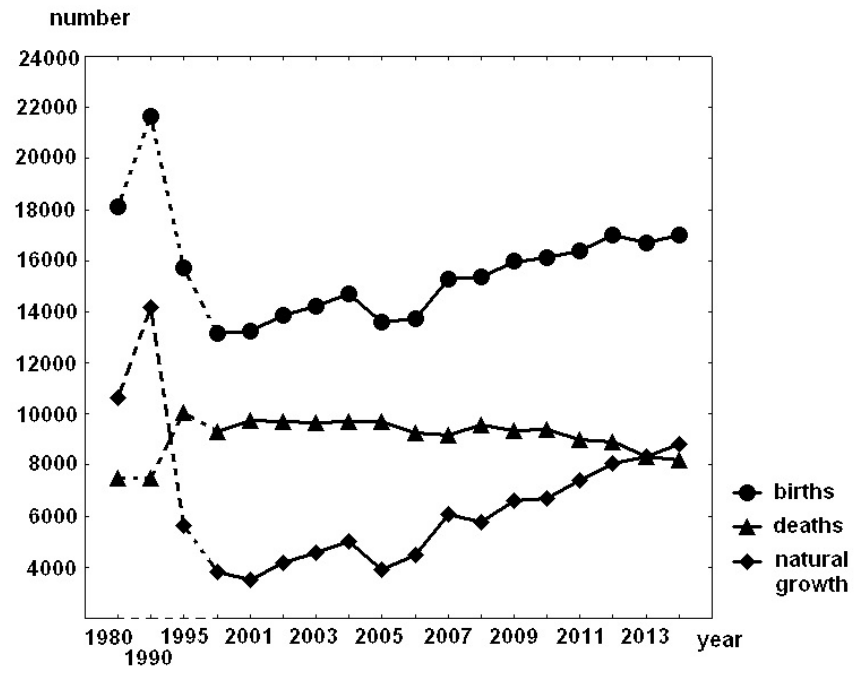

Fig. 1. Number of births, deaths and natural population growth in the RS(Y) since 1980 [5]

The abortion incidence is influenced by many medical and socioeconomic factors. In some way, it indicates the wellbeing of the population, and the abortion statistics can show the ways to improve medical services and to raise the living standards of people.

The objective of the study was to estimate the abortion incidence and to describe its current trends in the RS(Y).

\section{Materials and Methods}

The study was designed as a population-based descriptive study, based on the results of a longitudinal analysis of national and regional reports of the Yakut healthcare services and an analysis of medical records describing 34,220 abortions among women living in all regions of Yakutia, which occurred between 2010 and 2014 and in the first 9 months of 2015 .

Gestational age was determined according to the recommendations of the Committee on Obstetric Practice American Institute of Ultrasound in Medicine Society for Maternal-Fetal Medicine. ${ }^{[6]}$ Types of abortions were defined according to WHO recommendations. ${ }^{[7]}$

Statistical analysis was performed using the statistical software «Statistica» (v6.0, StatSoft, USA). Group comparisons with respect to categorical variables are performed using chisquare tests. A probability value of $P<0.05$ was considered statistically significant.

\section{Results}

The female population of the RS(Y) by age groups as of 2014 is presented in Table 1 . Around $50 \%$ of all women of Yakutia are of child-bearing age, a percentage which is higher than, for example, $43 \%$ in the USA as of July $2014,{ }^{[8]}$ and $46 \%$ in Russia in total as of January 2014. ${ }^{[9]}$ Moreover, the relative number of girls aged between 0 to 14 years in the female population of Yakutia is also greater: about $22 \%$ compared to $15 \%$ in Russia in total. ${ }^{[9]}$

Table 1.

The structure of female population of the RS(Y) in 2014

\begin{tabular}{|l|c|}
\hline \multicolumn{1}{|c|}{ Female population } & $\begin{array}{c}\text { absolute } \\
\text { number }\end{array}$ \\
\hline Total population & 954896 \\
\hline Females, total & 491349 \\
\hline women of child-bearing age $(15-49$ years old $)$ & 248115 \\
\hline adolescent girls $(15-17$ years old $)$ & 18793 \\
\hline girls $(0-14$ years old $)$ & 106232 \\
\hline
\end{tabular}

Trends in the number of abortions in Yakutia and in Russia in total by year are presented in Table 2. The absolute number of abortions performed each year, the rate of abortions per 1,000 women of fertile age, and the rate of abortions per 100 deliveries declined $(P<0.01)$ by about $37 \%, 32 \%$ and $37 \%$, respectively, between 2006 and 2014. The rate of abortions per 1000 women of fertile age in the first 9 months of 2015 decreased by $1.3 \%$, compared to the same period of $2014(P=0.05)$.

Table 2.

Number of abortions in the RS(Y) and in the Russian Federation in total [10-12]

\begin{tabular}{|l|c|c|c|c|c|}
\hline \multirow{2}{*}{ Year } & \multirow{2}{*}{$\begin{array}{c}\text { Absolute } \\
\text { number of } \\
\text { abortions }\end{array}$} & $\begin{array}{c}\text { Rate of abortions } \\
\text { per 1,000 women in } \\
\text { fertile age }\end{array}$ & \multicolumn{2}{c|}{$\begin{array}{c}\text { Rate of abortions per } \\
100 \text { deliveries }\end{array}$} \\
\cline { 3 - 6 } & & Yakutia & Russia & Yakutia & Russia \\
\hline 2006 & 14164 & 53.0 & 41.0 & 107 & 107 \\
\hline 2007 & 14090 & 53.0 & 38.0 & 95 & 92 \\
\hline 2008 & 13120 & 50.0 & 36.0 & 89 & 81 \\
\hline 2009 & 12059 & 44,6 & - & 78 & 74 \\
\hline 2010 & 10848 & 41.0 & 31.7 & 80 & 67 \\
\hline 2011 & 9900 & 38.1 & 30.5 & 71.9 & 63 \\
\hline 2012 & 9754 & 37.6 & 29.3 & 65.9 & 56.2 \\
\hline 2013 & 9105 & 35.8 & 28.3 & 71.3 & 53.7 \\
\hline 2014 & 8976 & 35.9 & 25.9 & 67.6 & 48.1 \\
\hline $2015^{*}$ & 6385 & 28.4 & - & 67.6 & - \\
\hline
\end{tabular}

*-the first 9 months

In 2015, the absolute number of abortions did not decrease in 16(47\%) regions of Yakutia and in the city of Yakutsk. The absolute number of abortions increased in 
Srednekolymsky $(+32 \%)$, Churapchinsky $(+24 \%)$, Niurbinsky $(+20 \%)$, Tattinsky $(+19 \%)$, Amginsky $(+18 \%)$, Bulunsky $(+17 \%)$, Verkhoyansky $(+16 \%)$, and Namsky $(+15 \%)$ regions. In the remaining 18 regions, the absolute number of abortions decreased, in 6 of them by more than $20 \%$.

Though the number of abortions in primigravida women decreases every year, the percentage of them is still rather high, especially at the age of 20 to 24 and 15 to 19 , accounting for approximately $2.4 \%$ of all abortions. It must be mentioned that 82 teen abortions were performed during the first 9 months of 2015 .

Changes in relative numbers of abortions before and after 12 weeks of pregnancy are shown in the Figures 2 and 3 . The relative number of miscarriages before 12 weeks of pregnancy increased during the last 3 years $(17.3 \%$ in 2012 vs $20.6 \%$ in $2014, P<0.000$ ), and this trend continued in 2015. The percentage of therapeutic and social abortions was the same, and the visible but slight decrease can hardly be interpreted even as a tendency $(71.7 \%$ in 2012 vs $70.7 \%$ in 2014, $P>0.05$ ). The percentage of unspecified abortions decreased from 2012 to 2014 ( $8.4 \%$ in 2012 vs $6.4 \%$ in 2014, $\mathrm{p}<0.000)$, but then increased in $2015(6.4 \%$ in 2014 vs $7.2 \%$ in 2015, $P<0.05$ ).

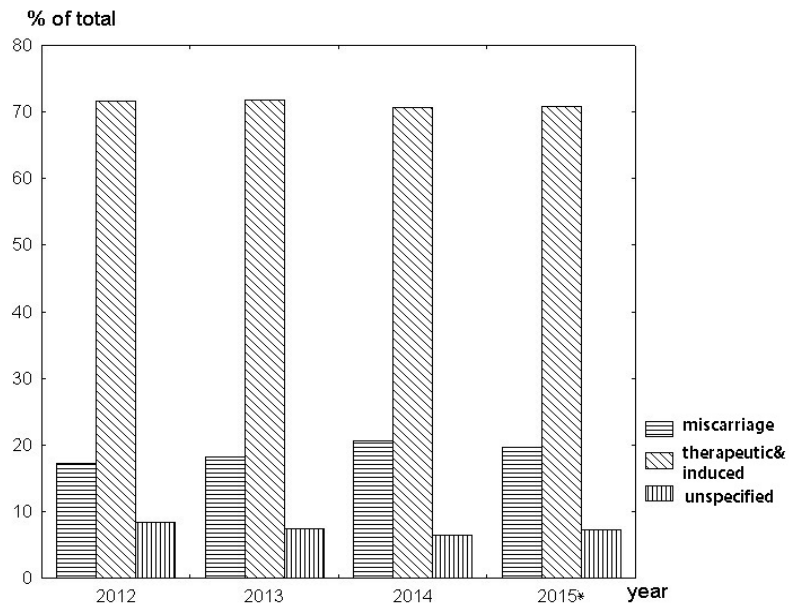

Fig. 2. Relative number of abortions before 12 weeks of pregnancy (\% of all abortions)

* - the first 9 months

Changes in the relative number of abortions performed between 12 and 21 weeks of pregnancy (Figure 3) were characterized by a decrease in the percentage of miscarriages from 2012 to 2014 (47.4\% in 2012 vs 40.3 in 2014, p<0.000) and a further slump in 2015, a dramatic increase in the percentage of therapeutic abortions (34\% in 2012 vs $45.5 \%$ in 2014 and $43.2 \%$ in 2015, $P<0.000$ ) and a decrease in the percentage of unspecified abortions from 2012 to 2014 $(17.4 \%$ vs $13.4 \%, P<0.000)$, with an unexplained increase by $10.7 \%(P<0.000)$ in 2015. In the first 3 quarters of 2015, the percentage of therapeutic abortions increased in 17 regions and in the city of Yakutsk. In Nizhnekolymsky, Momsky, Bulunsky, Churapchinsky and Ust'-Yansky regions, the increase was more than by $15 \%(P<0.01)$. The percentage of miscarriages decreased in 20 regions and increased in 11 regions and in the city of Yakutsk. A significant $(P<0.05)$ increase was revealed in Anabarsky (+24\%), Zhigansky $(+17 \%)$, Tattinsky $(+14 \%)$, Verkhnevilyuisky $(+7.1 \%)$ and Oymiakonsky $(+6.3 \%)$ regions.

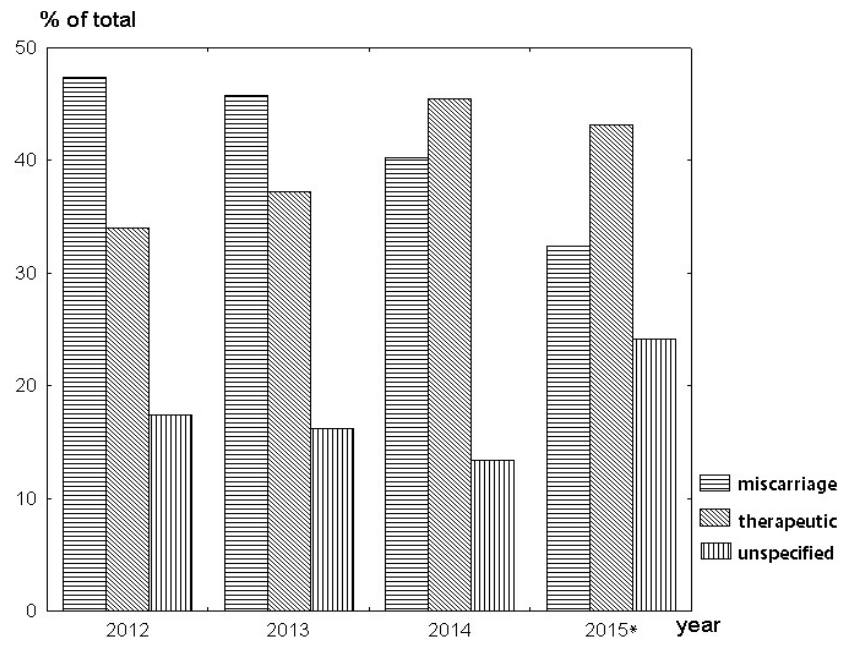

Fig. 3. Relative number of abortions between 12 and 21 weeks of pregnancy (\% of all abortions) * - the first 9 months

The percentage of different types of medical abortions is presented in Figure 4. From 2012 to 2014, the percentage of surgical abortions (D\&E) decreased $(68.1 \%$ in 2012 vs $63.6 \%$ in $2014, P<0.000$ ) with a further $6 \%$ drop in 2015 ; the percentage of vacuum aspirations also decreased $(29.4 \%$ in 2012 vs $15.4 \%$ in 2014 and 13.8 in $2015, P<0.000$ ), and the percentage of medication abortions changed dramatically ( $2.5 \%$ in 2012 vs $20.8 \%$ in $2014, P<0.000)$ with a further increase of almost $8 \%$ in 2015.

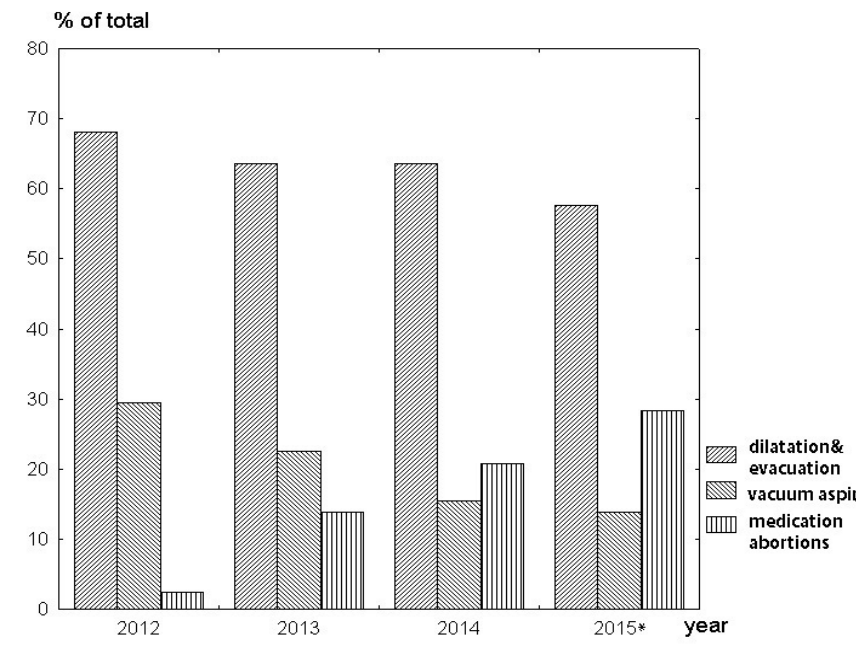

Fig. 4. Relative number of different types of therapeutic abortions (\% of all therapeutic and social abortions); *- the first 9 months

An increase in the percentage of medication abortions was due to successful implementation of the Regional Program of State Assurance, which since 2012 has included 
financial coverage for this kind of abortion. The result was that during only the first 9 months of 2015 the absolute number of medication abortions reached 1,214, which is almost twice as many as during the first 9 months of 2014. Of those 1,214 abortions, $75 \%$ were performed in the regions and only $25 \%$ in Yakutsk.

\section{Conclusion}

The revealed trends of the absolute number of abortions and the rates of occurrence in the $\mathrm{RS}(\mathrm{Y})$ can be considered in total as favorable, but compared to the data obtained in Russia in total, the dynamics of these trends cannot be regarded as satisfactory.

One of the most concerning issues is the multi-directional pattern of changes in different regions, which most probably depends on the quality of regional medical services, education, and socioeconomic status of the individual region. Differences in the incidence of abortions between regions were revealed, but it is unknown whether these differences can be assigned to lower standards of living in the inhabited locality with poor medical services rather than to ethnicity and the associated style of living. Analysis of spatial and temporal distribution of the incidence of abortions did not reveal any association with the ethnicity of women, though this analysis was based only on registered places of their habitation because ethnicity is not registered in the standard medical documentation.

Another matter of concern is the rather high incidence of abortions in adolescents and in primigravida women, which issue can be resolved only after a long period of teamwork with social services. The increase in the percentage of medication abortions within last 4 years is a positive trend, but the simplicity of performing them and the fact this procedure is free of charge can lead to an increase in the absolute number of abortions, especially in adolescents and young women.

An unsettling finding is a very high number of the socalled "unspecified" abortions. The absence of individual statistics on criminal abortions makes us suppose they are included in the "unspecified" group, though most probably this is just a fault of registration.

\section{Competing interests}

The authors declare that they have no competing interests.

\section{References}

1. Safe and unsafe induced abortion: Global and regional levels in 2008, and trends during 1995-2008. Geneva: WHO/ RHR; 2012.

2. Shah I, Ahman E. Unsafe Abortion in 2008: global and regional levels and trends. Reprod Health Matters. 2010;1836:90-101.

3. United Nations, World Population Policies Database (2013 Revision). Retrieved from http://esa.un.org/PopPolicy/ charting/worldmaps.aspx

4. World Factbook. Retrieved from https:/www.cia.gov/ library/publications/the-world-factbook/rankorder/2127rank.html

5. Annual Data of the Territorial Agency of the Federal Government Statistical Service in the Republic of Sakha (Yakutia). [in Russian]. Retrieved from http://sakha.gks.ru/ wps/wcm/connect/rosstat_ts/sakha/ru/statistics/population/

6. Committee opinion no 611: method for estimating due date. Obstet Gynecol. 2014; 124(4):863-6.

7. Definitions and indicators in family planning, maternal and child health and reproductive health. WHO Regional Strategy on Sexual and Reproductive Health. Geneva: World Health Organization; 2001.

8. Resident population of the United States by sex and age as of July 1, 2014. The Statistic Portal. [cited Mar 24 2016]. Retrieved from http://www.statista.com/statistics/241488/ population-of-the-us-by-sex-and-age/

9. Russian Statistical 2014 Yearbook. Federal State Statistics Services. [in Russian]. Retrieved from http://www.gks.ru/ bgd/regl/b14_13/IssWWW.exe/Stg/d01/04-05.htm

10. The Demographic Yearbook of Russia 2009. Federal State Statistics Services. Retrieved from http:/www.gks.ru/bgd/ regl/B09 16/IssWWW.exe/Stg/04-11.htm

11. The Demographic Yearbook of Russia 2015. Official Publication. Moscow: Federal State Statistics Services; 2015. p. 72. Retrieved from http://www.gks.ru/free doc/doc 2015/ demo15.pdf

12. Abortion/100 deliveries in Russian Federation. Central Database. Federal State Statistics Services. [in Russian]. Retrieved from http:/www.gks.ru/dbscripts/cbsd/dbinet.cgi?pl=7000088 